\title{
Experimental investigation and optimisation of the micro milling process of hardened hot-work tool steel
}

\author{
B. Z. Balázs ${ }^{1}$ (D) - M. Takács
}

Received: 19 September 2019 / Accepted: 24 January 2020 / Published online: 6 February 2020

(C) The Author(s) 2020

\begin{abstract}
In the past few decades, demand for precise miniature components has grown significantly. Modern production technologies required for the production of such components, including micro milling, have become extensively researched areas. In spite of the intensive research in this field, there are still many topics and aspects that merit investigation. Through a systematic series of experiments, this paper analyses the special characteristics of micro milling including cutting forces, vibrations, burr formation, and surface quality. A 5-axis micromachining centre with $60.000 \mathrm{rpm}$ maximum spindle speed was used for the experiments carried out in the scope of this paper, and the machining of hardened hot-work tool steel (AISI H13) with a hardness of 50 HRC was investigated in detail. Also, a special measurement environment was prepared in order to collect machining data. Based on the results of the experiments, a power regression prediction model for cutting forces was created. As part of the analysis in the scope of the experiments, fast Fourier transformation was carried out in order to analyse the dynamic characteristics of the micro milling process, and to determine dominant frequencies. In addition, an analysis of variance (ANOVA) was applied to extensively analyse the main effects and interactions of different cutting parameters on different characteristics. Based on the investigations carried out in a comprehensive parameter range, an optimal parameter combination was also determined. The results of the experiments introduced in this paper contribute to a deeper understanding of the micro milling process, and this research provides information directly applicable in the industry.
\end{abstract}

Keywords Micro milling $\cdot$ AISI H13 $\cdot$ Cutting forces $\cdot$ Vibrations $\cdot$ Signal analysis $\cdot$ ANOVA

\section{Introduction}

The kinematics and tools used in micro milling are similar to those used in the case of macro milling. Nevertheless, as compared to macro milling, the process of micro milling has a number of special characteristics due to the size effect. Micro milling is characterised by relatively large tool runout, strong burr formation, and rapid, unpredictable tool failure. Furthermore, the effect of workpiece material anisotropy, grain size, and crystalline errors play a significant role in the process [1]. Despite similar tool geometries, effective cutting angles show significant differences. Cutting edge radius $\left(r_{\beta}\right)$

B. Z. Balázs

balazs@manuf.bme.hu

1 Faculty of Mechanical Engineering, Department of Manufacturing Science and Engineering, Budapest University of Technology and Economics, Budapest, Hungary has more significant influence on chip removal mechanism in the scope of micro milling than in the case of conventional machining [2]. Also, new, unused carbide micro milling tools have a cutting edge radius between 1 and $20 \mu \mathrm{m}$, depending on whether they are coated or uncoated [3], which parameter of such tools is almost identical with that of conventional sized tools. The size of radius depends on the material of the tool, its grain size, manufacturing accuracy, and constantly changing tool wear conditions [4]. In the case of micro milling, cutting edge radius is comparable to chip thickness $[3,5,6]$, or grain size [7] of the workpiece material, and machining is completed using a strongly negative rake angle $[8,9]$. Minimum chip thickness $\left(h_{\min }\right)$ has utmost importance in the case of micro milling: it is well-known from the literature that below this chip thickness value, the main material removal mechanism is ploughing [10], in which case there is no shear, and the material is deformed only plastically and elastically, and there is no chip formation [8]. Given this, certain parameters in micro milling result in an ineffective way of material removal, and this also impairs the quality of the surface [11]. Biró and 
Szalay [12] extended an empirical specific cutting force model to the thin chip removal process, and identified a new knickpoint in the scale of micro chip formation. This phenomenon can be taken into account also in the case of micro milling. Due to the kinematics of the milling process, chip thickness continuously changes during a rotation. At very low feed rates, chip thickness may not reach the $h_{\min }$ value within a full rotation of the tool, so unremoved material layers accumulate, and the actual material removal occurs only after several turns [4]. According to many researchers, the value of $h_{\min }$ is the function of the cutting edge radius [9, 13-15]. Many studies unanimously place the $h_{\text {min }} / r_{\beta}$ ratio between 0.14 and 0.43 [9, $11,14,16-18]$ despite the variety of materials and methods. According to Bissacco et al. [8], the above-mentioned ratio has great influence on relative machining accuracy, burr formation, and surface quality. Based on this observation, it is expedient to increase feed per tooth $\left(f_{z}\right)$ for better machining, but the resulting larger forces and tool deformation have to be considered, too. Moreover, the radial immersion of the tool will be another important factor, because it also changes in the case of machining carried out along tool paths containing arcs and corners [19]. By increasing $f_{z}$, the ratio of ploughing to shear mechanism decreases.

One of the most important evaluation factors of the quality of microcomponents is surface roughness; therefore, many research efforts focus on this field. According to Aramcharoen and Mativenga [20], surface quality will be the best when theoretical chip thickness and cutting edge radius are the same. In this case, the ratio of conventional shear mechanism to the ploughing phenomenon will be appropriate for the process. With respect to SKD 61 material, $\mathrm{Li}$ and Chou [21] found that neither cutting speed nor feed rate have a significant effect on surface quality, although the effect of feed rate is dominant in the case of conventional chip separation. Mian et al. [22] analysed the roughness of micro milled surfaces using ANOVA, and found that the ratio of cutting edge radius to theoretical chip thickness, and cutting speed also play a determining role. Based on their study, it has been established that the impact of these factors on results are 28.05 and $28.57 \%$, respectively. Wang et al. [23] investigated surface characteristics at different stages of tool wear using Ti6Al4V material. According to their study, the main forms of surface defects are feed marks, material debris, plastic side flow, and smeared material. Most importantly, material debris and plastic side flow became more significant as wear progressed. Meanwhile, better surface quality was observed on the up-milling side as compared to the down-milling side. In another study, TiAlN coated micro milling tool with a 3.0 $3.5 \mu \mathrm{m}$ cutting edge radius and Ti6Al4V material were used by $\mathrm{K}$ and Mathew [24]. It was found that, in the case of $5 \mu \mathrm{m}$ feed per tooth value, surface roughness is reduced as wear progresses, and it shows a minimum value at the cutting length of $700 \mathrm{~mm}$, which is certain to be followed by deterioration. On the contrary, at $f_{z}=0.3 \mu \mathrm{m}$, roughness increases along with cutting length. According to the above authors, it is recommended that the feed per tooth value should be set slightly above the value of $r_{\beta}$ (with respect to surface roughness).

Prompted by the situation that cutting edge radius and other features of the tool continuously change due to wear, many research efforts regarding the effect of wear on cutting forces $[25,26]$ and on surface quality were carried out $[21,27]$. According to $\mathrm{Zhu}$ and $\mathrm{Yu}$ [27], tool wear affects surface integrity and product geometry. Furthermore, Uhlmann et al. [28] studied the interdependence between the roughness of machined surfaces and cutting edge radius in the case of X13NiMnCuAl4-2-1-1 material. With respect to AISI 4340 material, Afazov et al. [29] observed that cutting forces increase with the increase of cutting edge radius, because wear results in a longer contact section, and therefore increases friction. In addition to identifying an increase in cutting forces, while machining OFHC copper, Wu et al. [30] compared the ratio of shear force and ploughing force to cutting force (with shear force and ploughing force at 55 and $45 \%$, respectively) in the case of a cutting radius of $5 \mu \mathrm{m}$. As the radius increases, the difference shown in the study also increases. De Oliveira et al. [9] studied the effect of feed per tooth on specific cutting force in both macro and micro sizes. Doubling the feed per tooth value caused a $22 \%$ decrease in specific cutting force on average, and the doubling of the depth of cut caused a reduction of $13 \%$ in the case of micro size chip separation. At macro sizes, these values were only 18 and $7 \%$, respectively. Based on finite element simulations by Zhou et al. [31], who used NAK 80 , it can be stated that the effect of cutting speed on cutting forces is negligible in the range of $v_{c}=12-36 \mathrm{~m} / \mathrm{min}$ and $f_{z}=0.3-12 \mu \mathrm{m}$. In addition, cutting forces are also strongly influenced by the milling strategies applied, e.g. up-milling results in lower forces than down-milling when AISI 1045 is used (with width of cut being half the diameter of the tool) [32]. Analytical modelling and finite element simulations of cutting forces in the case of micro milling are also addressed by research [33-35]. De Oliveira et al. [9] modelled specific cutting forces, and they found that the models used in conventional sizes cannot be directly adapted to micro sizes. In addition, an analytical model was developed by $\mathrm{Lu}$ et al. [25] in order to estimate cutting forces: the model also takes into account the effect of flank wear. This model showed reasonable conformity with measurement results. Mamedov et al. [36] introduced a force model that takes instantaneous chip thickness, tool trajectory, ploughing force, and elastic recovery of the workpiece material into account. This model was also validated by experiments using $\mathrm{Al} 7075$.

On the other hand, the vibrations play an important role in the case of micro milling. Therefore, numerous research efforts are focused on the investigation of this characteristic. Jáuregui et al. [37] analysed the condition of the tool through 
an analysis of cutting force and vibration signals using fast Fourier transform and continuous wavelet transform (CWT). The impact frequency of tool edge (IPF) was used as a basis for analysing dominant frequencies of the process. In the case of a healthy tool, harmonic and nonharmonic components appear on nominal frequencies (1xIPF, 2xIPF, 3xIPF and $0.5 \mathrm{xIPF}, 1.5 \mathrm{xIPF}, 2.5 \mathrm{xIPF}$ ). However, in the case of a worn tool, the referent frequencies differ from the nominal value, and an appearance of further frequencies was observed. The study did not provide convincing evidence that the signal analysis by FFT or CWT could be applied as an indicator of tool wear. Yilmaz et al. [38] investigated the dynamics of micro milling tools. The method presented in their study is based on inverse stability analysis, where modal parameters are updated by the results originating from chatter tests in order to achieve a better approximation of the dynamic behaviour of the tip of the micro tool. Since the frequency response function (FRF) of the tool tip is essential for determining stability limits, the authors presented an analytical model which can provide data for FRF. Singh et al. [39] also studied the dynamics of micro milling tools. A finite element modal analysis was used to determine FRF, and the results were validated by experiments. The difference between the results of the $1^{\text {st }}$ mode natural frequency determined by the two methods was only $6.6 \%$. The natural frequencies of the first, second, and third modes of the studied tool were 4851, 5081, and $7170 \mathrm{~Hz}$, respectively. In fact, these values fall in the range as the characteristic frequencies of micro milling process.

Another major problem of the micro milling process is strong burr formation, which depends primarily on the actual state of the tool and on the workpiece material, but machining strategy and cutting parameters play also an important role in this respect. In the case of micro milling, burr size can reach almost the diameter of the tool, which greatly affects the quality of the machined component [40], and impairs its performance [5, 41]. Removing burr poses a huge challenge concerning micro sizes [5, 42]; therefore, one of the main directions of research in the case of micro milling is reducing burr formation during machining. In the scope of this effort, researchers analysed the effect of milling strategies on burr formation using a number of workpiece materials such as OFHC [43], Inconel 718 [22], Ti6A4V [26], AA1100 [40], AISI 1045 [1], Al6061-T6 [44], and X5CrNi18-10 [45]. In these studies, burr was identified to be larger mostly on the down-milling side, but there are some contrary results too [46]. Wu et al. [43] suggested a subsequent milling operation carried out on the up-milling side in order to remove burr. Actually, the structure and the size of burr can rapidly change during the process. According to Mian et al. [22], burr on the down-milling side is more uniform. Saptaji and Subbiah [44], as well as
Biermann and Steiner [45], observed higher quality on the down-milling despite larger burr. Mian et al. [22] found that burr root thickness is primarily influenced by cutting speed and the $h_{\min } / r_{\beta}$ ratio. Aramcharoen and Mativenga [20] investigated micro milling of hardened H13, and they found that the larger the ratio between undeformed chip thickness and cutting edge radius the smaller the burr size, which can be caused by the phenomenon of reduced ploughing. Kumar et al. [41] emphasised the complexity of burr formation, because the material properties of the workpiece, tool geometry, coatings, as well as cooling and lubricating also influence burr formation besides cutting parameters. According to Komatsu et al. [47], a decrease in the grain size of the $\mathrm{X} 5 \mathrm{CrNi} 18-10$ material facilitates reduced burr formation. In the case of normal grain sizes (on average $9.1 \mu \mathrm{m}$ ), cutting force suddenly decreases at the end of the cutting process with accompanying changes in shear angle, and relatively large burr continues to be present on the edge. In contrast, in the case of ultra-fine grained materials (on average $1.52 \mu \mathrm{m}$ ), force reduction occurs gradually at the end of chip separation, which results in smaller burr. According to Bai et al. [48], burr formation is significantly influenced by the properties of the applied material and its microstructure in the case of machining ASTM A131 material. Working with AISI H13, Aramcharoen and Mativenga found that tool coating also favourably impacts the reduction of the size of burr [7]. Swain et al. [49] compared burr size when machining Niomic 75 using uncoated and nanostructured TiAlN coated tools. It was found that, at the beginning of the cutting length, tools yield almost the same quality, but later stronger wear of uncoated tools will result in larger burr.

In the above section, cutting forces, vibration, surface quality, and burr formation were discussed in detail, as well as the relevant literature on the role of the size effect and the cutting edge radius was introduced, as these topics are related to the most important phenomena of micro milling. However, relatively few publications deal with a detailed comparison of milling strategies. As suggested by the review of the literature, it is also clear that in the case of burr formation, there are contradictory statements regarding dominant burr size. Moreover, studies typically focus only on one of the main problems of the micro milling process, and they do not give an overall analysis of the process itself. At the same time, there are some excellent summary-purpose books and review papers regarding micro milling, which also highlights the importance of the complexity of this issue $[50,51]$.

In fact, hardened steels are of essential importance in the modern industry, and they can serve, among others, as a material of micro-injection moulding tools. As a matter of fact, only a limited number of publications are available that deal 
Fig. 1 Measurement layout inside the machine

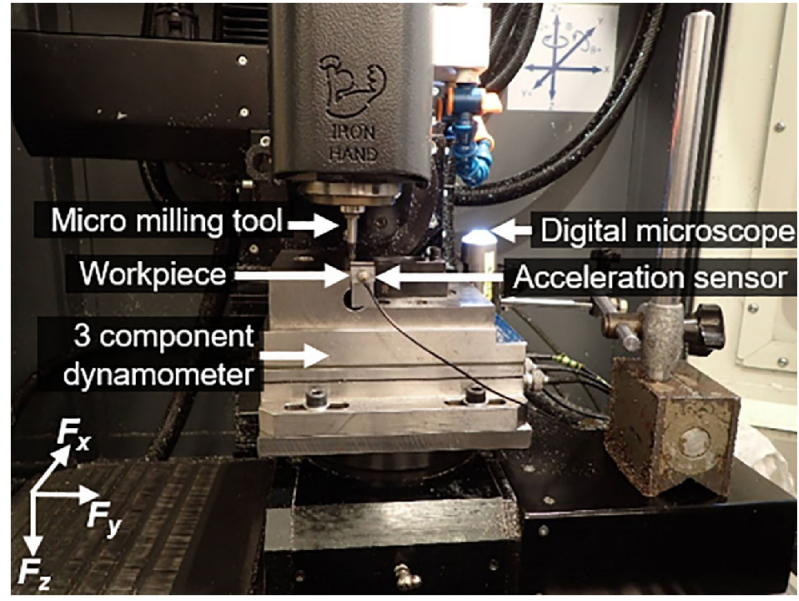

\section{Experimental set-up}

The experiments were carried out using a VHTC $130 \mathrm{M} 5$-axis micromachining centre with a maximum spindle speed of $60.000 \mathrm{rpm}$. The machining environment and measurement layout are shown in Fig. 1.

Force measurement was provided by a three-component Kistler 9257A dynamometer and a Kistler 5080A charge amplifier. Vibrations were recorded with the help of a Brüel \& Kjaer 4518-001 one-component piezoelectric acceleration sensor with a sensitivity of $10.2 \mathrm{mV} / \mathrm{ms}^{-2}$ and a measurement range of 1 to 20,000 Hz. A Dino-Lite AMT413T5 digital microscope with $\times 500$ magnification was installed for checking the condition of the tool. NI USB-4431 devices and LabVIEW software were applied for data collection and analysis. The diameter of the two fluted, coated carbide micro milling tool was $500 \mu \mathrm{m}$, and the measured rake angle $(\gamma)$ and clearance angle $(\alpha)$ were -10 and $13.7^{\circ}$, respectively, and the helix angle $(\lambda)$ was $25^{\circ}$. The tool has a $50 \mu \mathrm{m}$ corner radius, which contributes to the stability of the cutting edge. The main geometrical characteristics of the micro milling tool can be seen in Figs. 2 and 3.

All experiments were carried out in the uniform wear section of the wear curve; therefore, the effect of tool degradation

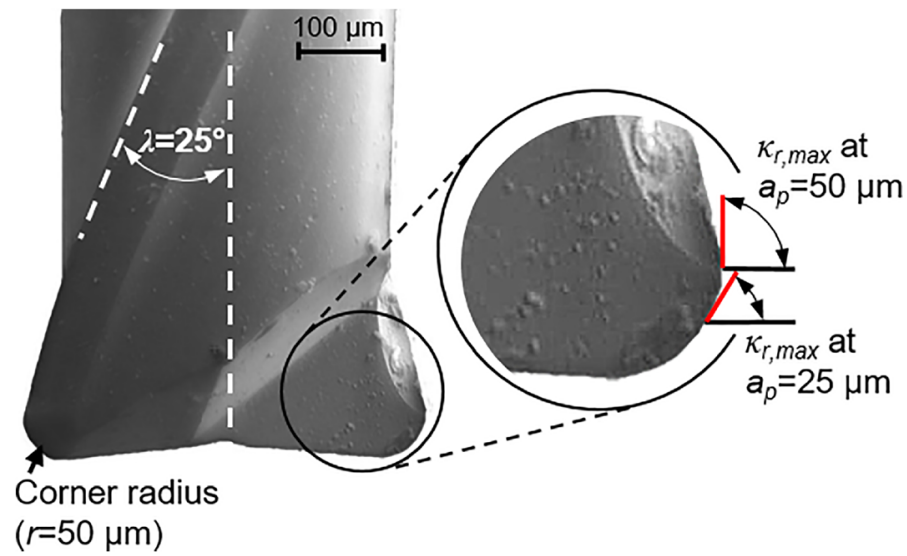


Table 1 Chemical composition of AISI H13 [34]

\begin{tabular}{llllll}
\hline $\mathrm{C}(\%)$ & $\mathrm{Si}(\%)$ & $\mathrm{Mn}(\%)$ & $\mathrm{Cr}(\%)$ & $\mathrm{Mo}(\%)$ & $\mathrm{V}(\%)$ \\
\hline 0.39 & 1.10 & 0.40 & 5.20 & 1.40 & 0.95 \\
\hline
\end{tabular}

was minimised. Based on images produced by scanning electron microscopes, it has been established that the cutting edge radius of an unused tool is in the range of $2-4 \mu \mathrm{m}$. The experiments were performed without any coolant or lubricant. The run-out of the clamped micro milling tool was 0 . Hardened AISI H13 of 50 HRC was used as workpiece material. The hardness of $50 \pm 1 \mathrm{HRC}$ was ensured by a professional heat treatment process carried out by voestalpine BÖHLER Hungary. The chemical composition of the material is shown in Table 1.

Considering the diameter of the tool and the maximum available spindle speed, a cutting speed of $90 \mathrm{~m} / \mathrm{min}$ was applied. The size of the corner radius was also taken into account when determining the values of the depth of cut (Fig. 2), since the depth of cut also affects the main cutting edge angle $\left(\kappa_{r}\right)$. Upon determining the range of feed per tooth values, cutting edge radius was taken into account, and values were selected below and above $r_{\beta}$. Geometric conditions are illustrated in Fig. 3 with the help of 3 examples from the experiment design.

When $f_{z}<r_{\beta}$, the impact of the ploughing phenomenon is present for a longer period of time during one rotation of the cutting edge (see Fig. 4), and the size effect is stronger. Based on this, the smallest $f_{z}$ value was chosen close to the assumed minimum chip thickness (Fig. 3a). Figure 3 also shows the change of the effective rake angle $\left(\gamma_{e}\right)$ in the case of low theoretical chip thickness.

Milling strategy significantly affects the kinematics of the milling process, so in the scope of the present study milling strategies were investigated, too. Related factors and levels are shown in Table 2. All parameter combinations were tested, which means a total of 63 different

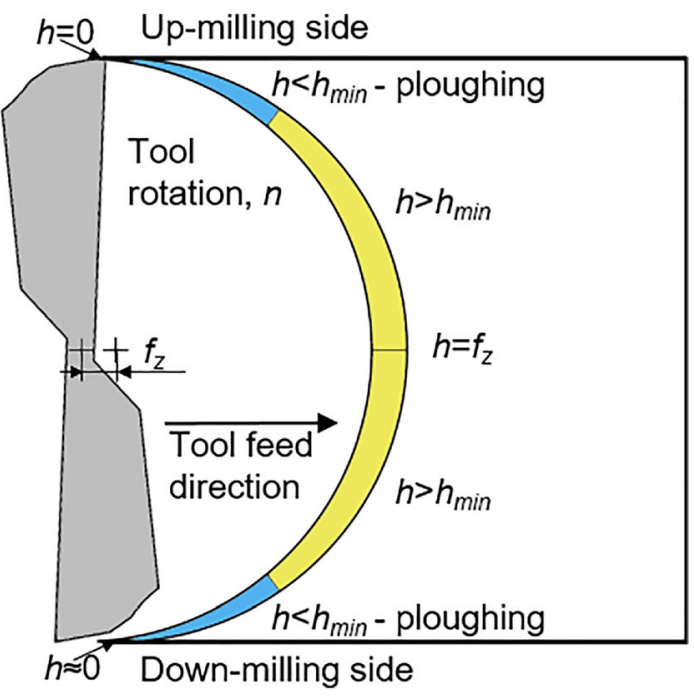

Fig. 4 Change of chip thickness during micro milling

settings. A cutting length of $5 \mathrm{~mm}$ was applied at each parameter setting.

\section{Results and discussion}

\subsection{Analysis of the cutting force}

Cutting forces have a direct effect on the deformation of the tool and provide a considerable amount of information about the cutting process including chip formation, material removal mechanisms and vibrations [52, 53]. Having clear information on cutting forces is an essential condition for designing a repeatable micro milling process. Cutting force $\left(F_{c}\right)$ and axial force $\left(F_{z}\right)$ are the most relevant components of resultant force when milling takes place. Cutting force $\left(F_{c}\right)$ consists of force components which act perpendicular to the tool axis. Equation (1) shows the determination of the $F_{c}$ component.

$$
F_{C}=\sqrt{F_{x}^{2}+F_{y}^{2}}
$$

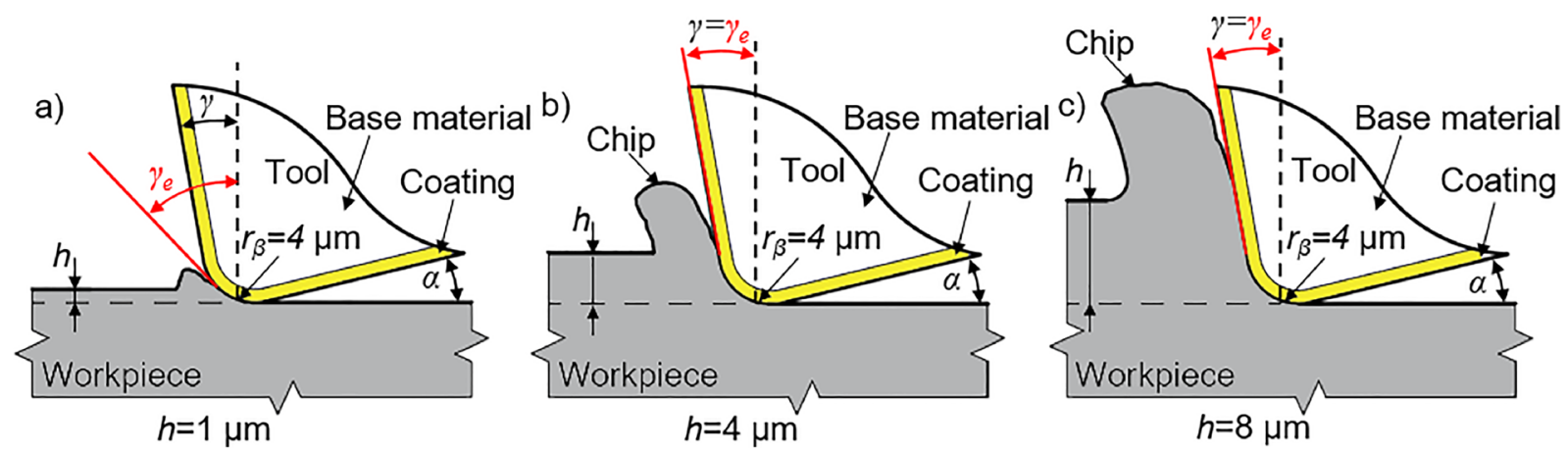

Fig. 3 Geometrical conditions and chip separation at the different feed per tooth values 
Table 2 Applied cutting parameters

\begin{tabular}{llll}
\hline Factors & $a_{p}(\mu \mathrm{m})$ & $f_{z}(\mu \mathrm{m})$ & Milling strategy \\
\hline Levels & $25 ; 50 ; 100$ & $1 ; 2 ; 4 ; 6 ; 8 ; 10 ; 12$ & $\begin{array}{l}\text { down-milling using half diameter of the tool, up-milling using half diameter of the tool, } \\
\text { full-groove milling }\end{array}$ \\
\hline
\end{tabular}

In this research work, $F_{c}$ and $F_{z}$ values were calculated as an average of the maximum force values of 100 rotations. For the purpose of performing experiment-related evaluations, a software application was developed in a LabVIEW environment: the results are shown in Fig. 5. $F_{c}$ values were increased along with increasing both the depth of cut and the feed per tooth values, which is explained and underpinned by an increase in the chip cross-section. In this respect, there is no significant difference between down- and up-milling strategies. Of course, in the case of full-groove milling, larger forces were measured because of the double amount of removed material.

In the case of down-milling at $a_{p}=25 \mu \mathrm{m}$ depth of cut, it was realised that a 12 times higher increase of feed per tooth causes a mere $29.74 \%(1.55-2.35 \mathrm{~N})$ rise in cutting force. In the case of the up-milling process, this force increase is approximately twofold, which can also be considered small. The reason for such a small change described here is due to the small depth of cut. In this case, the instantaneous main cutting edge angle $\left(\kappa_{r}\right)$ is small due to the corner radius (as can be seen in Fig. 2), which results in chip thinning phenomena, therefore $F_{c}$ forces show only a slight increase. Due to the corner radius and the small depth of cut, cutting conditions are similar to circumstances associated with the high feed milling (HFM) process. Therefore, in the case of this depth of cut, setting high feed per tooth values is recommended.

In the case of down-milling at $a_{p}=50 \mu \mathrm{m}$ depth of cut, a sudden increase of $F_{c}$ is observed around $f_{z}=4-6 \mu \mathrm{m}$, which is followed by a very slight growth, although the feed per tooth value actually doubles. The main reason for that can be explained by achieving favourable machining conditions for the given geometric conditions, where the dominant material removal mechanism is shearing rather than ploughing.

The tendency shown by the $F_{z}$ force component is quite similar to the change in cutting force $\left(F_{c}\right)$. In the case of using a down-milling strategy with $a_{p}=25 \mu \mathrm{m}, F_{z}$ forces increased from 3.08 to $4.15 \mathrm{~N}$, which means a change of $34.74 \%$, even if productivity was 12 times higher as a result of increased feed per tooth values. In the case of $a_{p}=50 \mu \mathrm{m}$, a sudden growth can be observed around 4-6 $\mu \mathrm{m}$ feed per tooth value (from 3.64 to $5.02 \mathrm{~N}$ ) too; but the additional doubling of $f_{z}$ did not alter the forces significantly. At larger depth of cut values $\left(a_{p}=100 \mu \mathrm{m}\right)$, where the chip thinning effect is less significant, cutting force
Fig. 5 Relationship between cutting forces and cutting parameters; $\mathbf{a}$ and $\mathbf{c}$ : in the case of using the full-groove milling strategy, and $\mathbf{b}$ and $\mathbf{d}$ : in the case of using the down-milling strategy
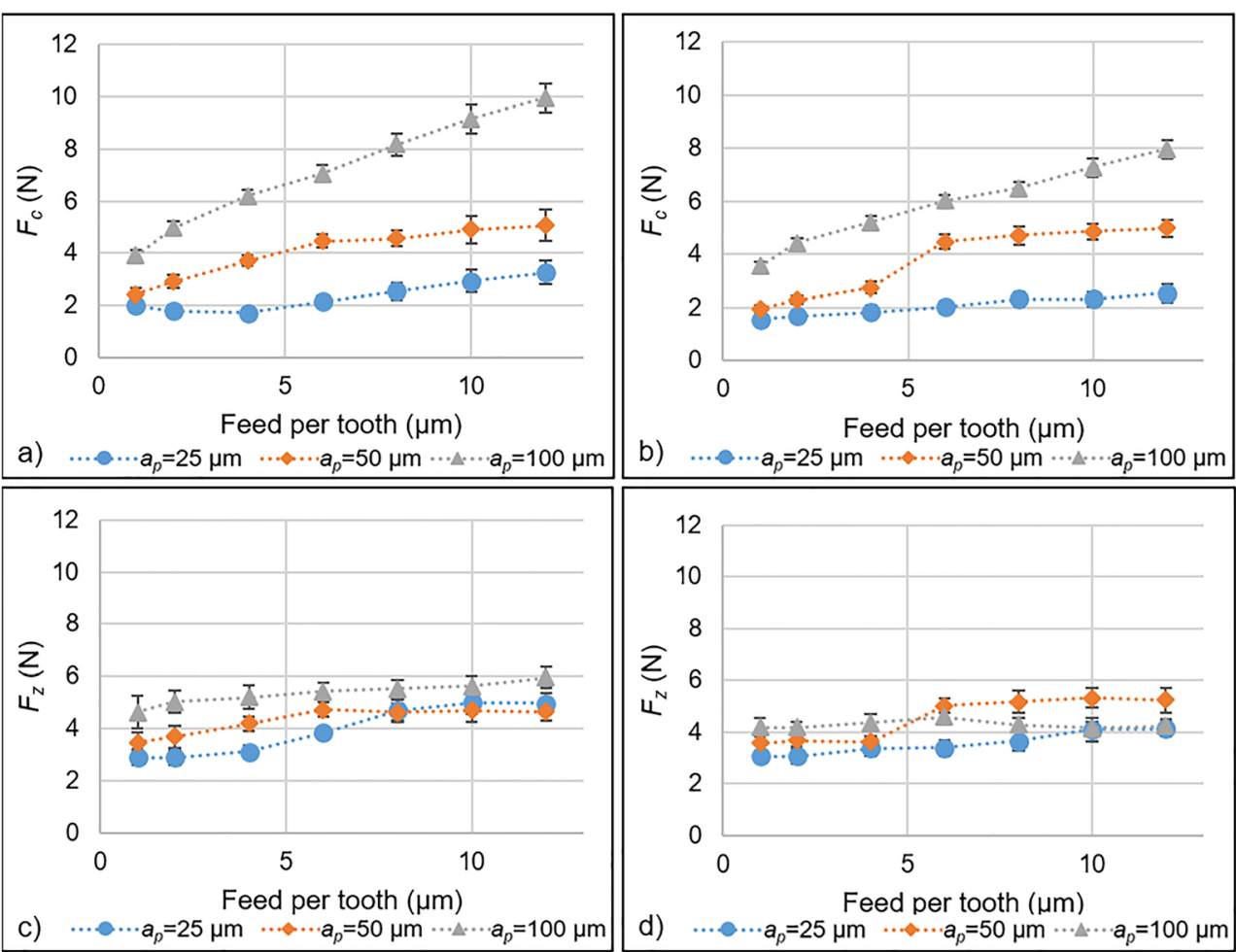
Fig. 6 a Cutting force measured at different feed per tooth values, b comparative display of cutting force calculated with the help of mathematical models and discrete measurement points obtained during the experiments

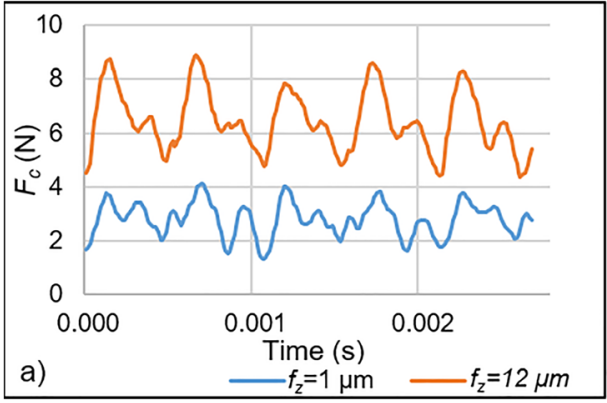

shows a more dominant increase, while the change of $F_{z}$ remains limited.

Based on the diagrams shown in Fig. 5, it can be concluded that in the case of both up- and down-milling strategies, the difference between $F_{z}$ values are smaller than that between the $F_{c}$ values. Above $f_{z}=6 \mu \mathrm{m}$, smaller depth of cut can even result in a larger axial force. This is explained by the special effects of smaller actual $\kappa_{r}$, which is due to geometric conditions, and the effect of the helix angle.

Figure 6a) shows changes in cutting force without any filtering. The lower curve was recorded at $f_{z}=1 \mu \mathrm{m}$, and the upper one relates to $f_{z}=12 \mu \mathrm{m}$. In general, it can be stated that the larger the feed per tooth value is, the more separable the run of the signal of each cutting edge is. This indicates a more stable cutting process. There is also a clear increase in forces, both in absolute terms and in ranges. This increase was expected due to an increase in chip cross-section. Furthermore, it can also be observed that $F_{c}$ does not decrease to zero either before the moment of entering or after exiting the cutting edges. This means that the tool is under continuous load, which indicates that elastic deformation of the system cannot be eliminated during the cutting process.

The deflection of the tool is mainly caused by the forces acting in the plane perpendicular to the axis of the tool. Mathematical models with power regression were created for different milling strategies, which closely match the values measured during the experiments. Since the deflection of the micro milling tool is primarily influenced by cutting force, the proposed model can be a good basis for such kind of research in the future. Theoretical chip thickness $(h)$ changes from point to point along the radius of the applied micro milling tool featuring a corner radius, so it was decided to use the maximum chip cross-section $\left(A_{\max }\right)$ instead of $h$ (Eq. (2)):

$A_{\max }=f_{z} \cdot a_{p}\left(\mathrm{~mm}^{2}\right)$

where $A_{\max }$ is the maximum chip cross-section $\left(\mathrm{mm}^{2}\right), f_{z}$ is the feed per tooth (mm), and $a_{p}$ is the depth of cut (mm). In the mathematical model, the contact length of the cutting edge $\left(l_{c}\right)$ was also taken into account due to frictional conditions, which play an important role in micro milling due to the ploughing effect. The mathematical model of cutting forces in the case of full-groove milling is shown in Eq. (3).

$F_{c, f u l l}=1.236+1220 \cdot A_{\max } 0.4872 \cdot l_{c}^{0.82}(N)$

The correlation of the model to the measured data is 99.23\%. The model described in Eq. (4) yields the forces of up-milling with a correlation of $99.08 \%$.

$F_{c, u p}=0.6393+267 \cdot A_{\max }^{0.4057} \cdot l_{c}^{0.4638}(N)$

Finally, the mathematical model of down-milling is shown in Eq. (5): here the correlation is $97.25 \%$.

$F_{c, \text { down }}=0.02119+212,8 \cdot A_{\max }{ }^{0.3438} \cdot l_{c}^{0.4845}(N)$

Based on the correlation values obtained, the models presented above, through offering good approximation, are able to describe and predict measured results. The graphical

Table 3 Validation of the cutting force model

\begin{tabular}{|c|c|c|c|c|c|}
\hline$f_{z}(\mu \mathrm{m})$ & $a_{p}(\mu \mathrm{m})$ & $F_{c}$ calculated $(N)$ & $F_{c}$ measured $(N)$ & Variance $(N)$ & Error \\
\hline 2 & 75 & 3.841 & 3.594 & 0.202 & $6.42 \%$ \\
\hline 6 & 75 & 5.684 & 5.391 & 0.384 & $5.16 \%$ \\
\hline 3 & 100 & 5.595 & 5.849 & 0.275 & $4.53 \%$ \\
\hline 5 & 100 & 6.827 & 6.870 & 0.311 & $0.63 \%$ \\
\hline 14 & 100 & 10.469 & 11.073 & 0.372 & $5.76 \%$ \\
\hline 16 & 100 & 11.090 & 12.053 & 0.463 & $8.68 \%$ \\
\hline
\end{tabular}




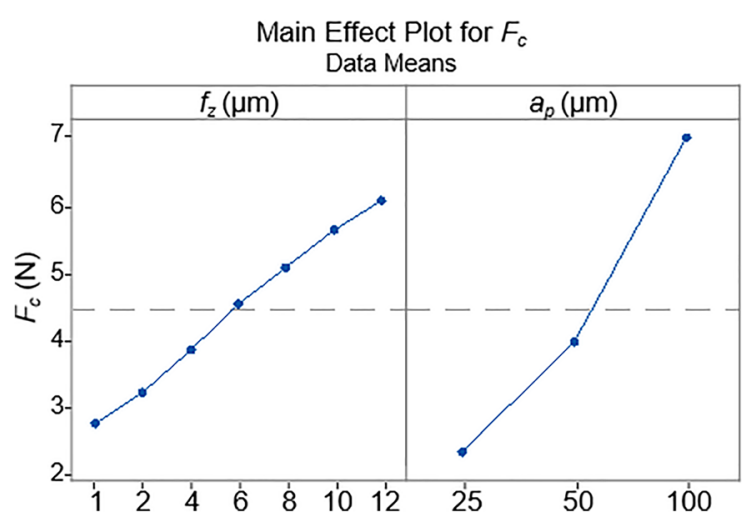

Fig. 7 Main effect plots for force components

representation of the approximation under the investigated circumstances is shown in Fig. 6b.

In order to validate the model, further experiments were carried out using different parameter combinations in the case of full-groove milling. The results are shown in Table 3. Based on these experiments, it can be stated that the model offered in the scope of this paper is able to offer approximations with respect to all results.

As part of the evaluation of forces, analysis of variance was carried out in order to perform a detailed examination of fullgroove milling. The main effects of both feed per tooth and depth of cut were analysed (Fig. 7). In both cases, a clear trend can be seen: an increase of the parameters results in larger forces within the investigated range of parameters. In the statistical analysis, the $F_{\text {crit }}$ value was 4.381 at a significance level of $95 \%$. In the case of $F_{c}$, the main effect of $f_{z}$ is $3.328 \mathrm{~N}$ ( $F$ value: $420.85, P$ value: 0.000$)$, and the main effect of $a_{p}$ is $4.714 \mathrm{~N}$ ( $F$ value: $1132.45, P$ value: 0.000 ). Thus, it can be stated that cutting depth has a larger effect on cutting force. Corresponding ANOVA data are shown in Table 4 (in the other cases, only the $F$ and $P$ values are given). In contrast, the main effect of $f_{z}$ is larger $(1.526 \mathrm{~N}, F$ value: $77.54, P$ value: $0.000)$ on the axial force $\left(F_{z}\right)$ than that the main effect of $a_{p}$, where the same value is $1.42 \mathrm{~N}$ ( $F$ value: $93.38, P$ value: $0.000)$.

Table 4 ANOVA table for forces $F_{c}$

\begin{tabular}{lrrrrr}
\hline Source & DF & Adj SS & Adj MS & $F$ value & $P$ value \\
\hline Model & 3 & 116.374 & 38.7914 & 520.90 & 0.000 \\
Linear & 2 & 114.417 & 57.2084 & 768.20 & 0.000 \\
$f_{z}$ & 1 & 31.341 & 31.3410 & 420.85 & 0.000 \\
$a_{p}$ & 1 & 84.334 & 84.3339 & 1132.45 & 0.000 \\
2 -way interactions & 1 & 8.768 & 8.7682 & 117.74 & 0.000 \\
$f_{z}^{*} a_{p}$ & 1 & 8.768 & 8.7682 & 117.74 & 0.000 \\
Error & 17 & 1.266 & 0.0745 & & \\
Total & 20 & 117.640 & & & \\
\hline
\end{tabular}

Main Effect Plot for $F_{z}$ Data Means

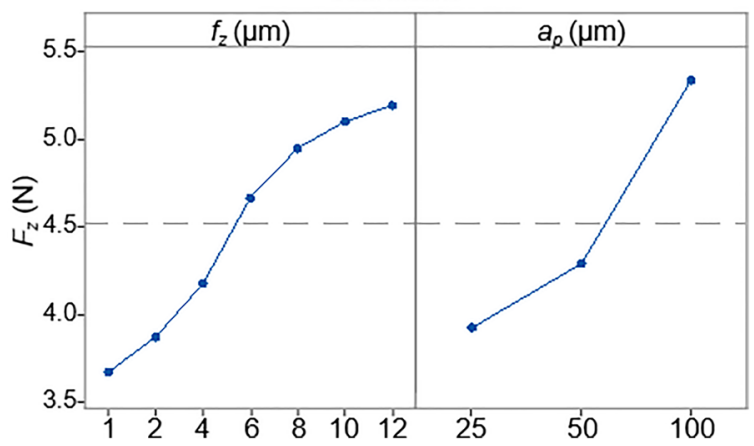

Based on the analysis, it can be stated that the interaction between parameters $f_{z}$ and $a_{p}$ is significant in the case of both forces. For cutting force $\left(F_{c}\right)$, the $F$ value and the $P$ value are 117.74 and 0.000 , respectively, while these values are 8.3 and 0.010 in the case of axial force $\left(F_{z}\right)$.

\subsection{Results of vibration measurement}

The micro milling process is characterised by strong vibrations, which are partly due to the size effect and partly to milling kinematics. The deformation of the slight tool, its run-out, and the properties of the workpiece material, all contribute to the formation of vibration. Information regarding vibration can be gained by analysing both the force signal and the vibration signal. Below, a summary of the results of the analysis of the signals recorded by the one-component piezoelectric accelerometer will be detailed. During signal processing, the average of the highest 100 values was considered as the maximum value shown in the diagrams of Fig. 8.

Based on the investigations, it can be concluded that the smallest vibration amplitudes are observable in the case of full-groove milling. This phenomenon can be explained by the contact number of $\psi=1$, which is more favourable than the contact number specific to shoulder milling strategies. At a depth of cut of $a_{p}=25 \mu \mathrm{m}$, the referent values vary in a relatively small range (from 8.67 to $13.36 \mathrm{~m} / \mathrm{s}^{2}$ ). The smallest amplitude $\left(8.67 \mathrm{~m} / \mathrm{s}^{2}\right)$ can be found at the parameter combination of $a_{p}=25 \mu \mathrm{m}$ and $f_{z}=8 \mu \mathrm{m}$, and the minimum value $\left(13.26 \mathrm{~m} / \mathrm{s}^{2}\right)$ at the parameter combination of $a_{p}=100 \mu \mathrm{m}$ and $f_{z}=4 \mu \mathrm{m}$, which is followed by a marked increase. The reason for the different minimum values at different depths of cut lies in differences concerning chip cross-sections. In contrast, in cases where the depth of cut corresponds to the corner radius $\left(a_{p}=\right.$ $50 \mu \mathrm{m}$ ), the highest vibrations measured were at $f_{z}=$ $4 \mu \mathrm{m}$. In this case, a further increase of feed per tooth has a positive effect on vibration amplitude. In fact, it can be seen that the curves of the different depth of cut values 
Fig. 8 Results recorded by the one component piezoelectric vibration sensor in the case of a the full-groove milling strategy and $\mathbf{b}$ the down-milling strategy
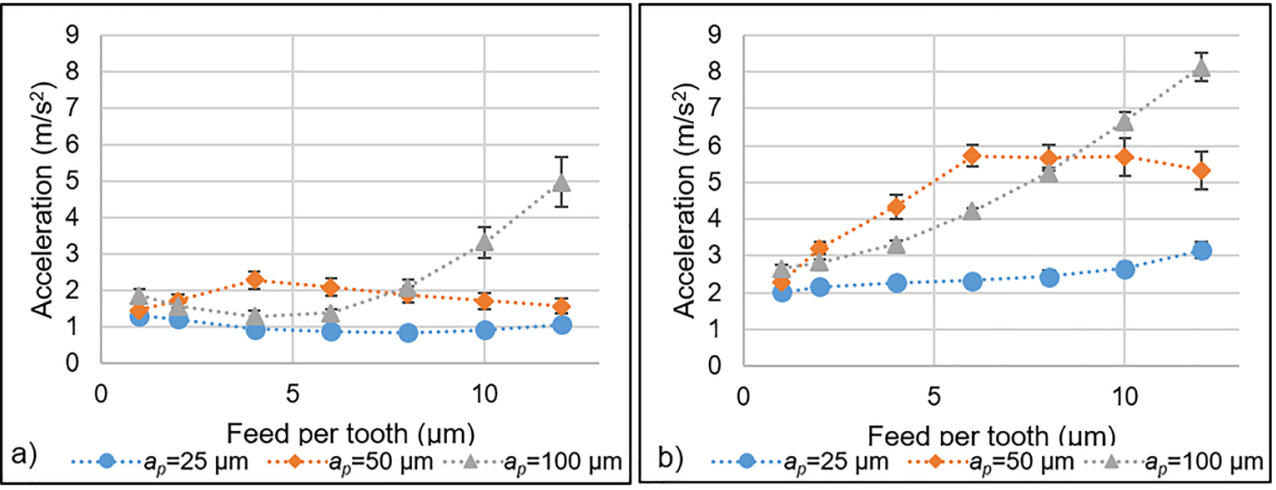

( $a_{p}=50$ and $a_{p}=100 \mu \mathrm{m}$ ) cross each other. For example, at $a_{p}=100 \mu \mathrm{m}$, the curve has a minimum value of $f_{z}=4 \mu \mathrm{m}$, which means that productivity has doubled, and the condition of vibration is more favourable than in the case of $a_{p}=$ $50 \mu \mathrm{m}$. The crossing of the two curves is located at a feed per tooth value of $8 \mu \mathrm{m}$.

After the comparison of the milling strategies, it was found that vibration circumstances are worse in the case of the downmilling strategy. The reason for this may be the repeated entry of the cutting edges into the material due to the kinematics of milling, which means periodic excitation (at certain time intervals). In the case of down-milling, a micro milling tool of limited stiffness enters the material at maximum chip thickness. By contrast, in the case of up-milling, the tool enters the material of a chip thickness of 0 , and chip thickness gradually increases to the maximum value during rotation. Therefore, the down-milling strategy results in stronger excitation than the up-milling process. At $a_{p}=100 \mu \mathrm{m}$, a strong increase of vibration can be seen with respect to all three strategies. The vibration can be evaluated as favourable up to a feed per tooth value of $8 \mu \mathrm{m}$. Considering technological and financial aspects - such as higher material removal rate and costefficiency - this feed per tooth value can be selected as an appropriate parameter for industrial purposes.

Figure 9 shows the main effect and the interaction plots of the cutting parameters investigated. It was observed that the main effect of the depth of cut $\left(13.56 \mathrm{~m} / \mathrm{s}^{2}\right)$ is larger ( $F$ value: $21.67, P$ value: 0.000 ) than that of the feed per tooth, and such values show a clear trend. The increase of the depth of cut results in larger vibration in the investigated parameter range. The secondary parameter is the feed per tooth, which has only a modest effect on vibrations in the range of $f_{z}=1 \mu \mathrm{m}$ and $f_{z}=8 \mu \mathrm{m}$, but its further increase causes a significant change in vibrations. This can be explained by the kinematics of the milling process. At higher feed per tooth values, when the cutting edge enters the material, the force grows faster since the tool reaches thicker chips earlier (Fig. 4), and this generates more powerful vibrations due to periodically repeating higher force impulses. The main effect of the feed per tooth is $11.12 \mathrm{~m} / \mathrm{s}^{2}$ ( $F$ value: $8.77, P$ value: 0.009$)$. Also, it was found that there is strong interaction between the parameters of feed per tooth and depth of cut ( $F$ value: 15.97, $P$ value: 0.001 ).

Furthermore, dominant frequencies of the recorded force signals were analysed by fast Fourier transformation. The knowledge of typical frequencies contributes to a better understanding of the dynamics and periodicities of the micro milling process. As part of the frequency analysis, all the three force components were considered separately, because this methodology provides the most insightful results about vibrations.
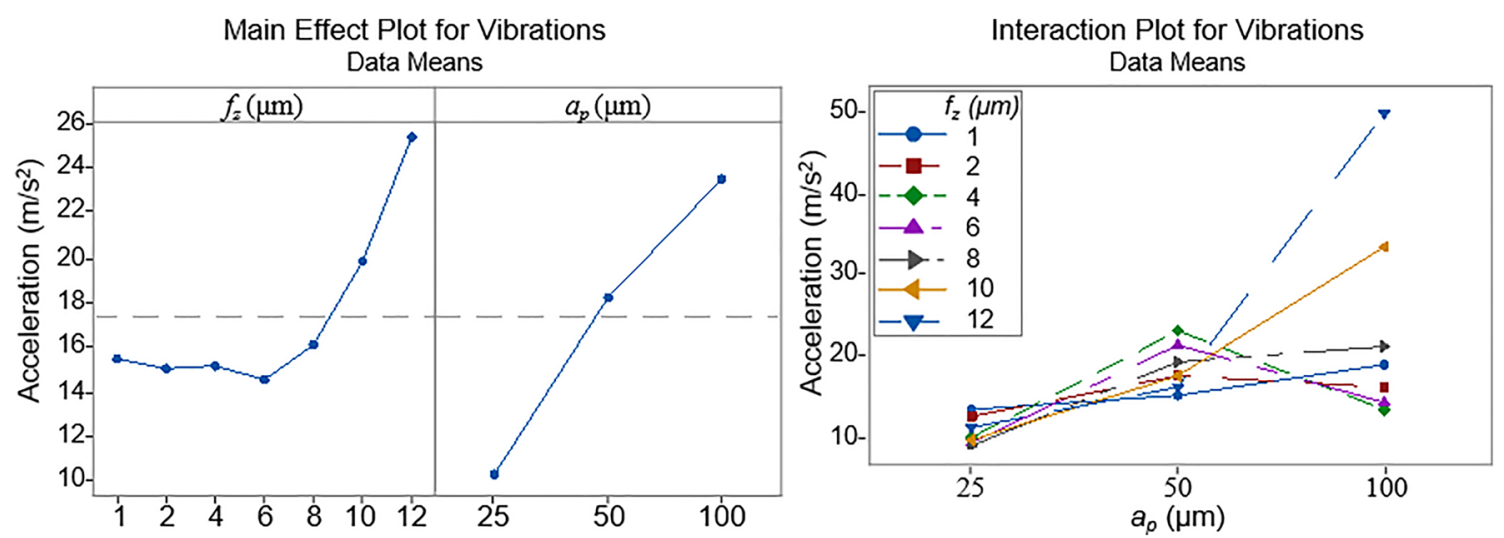

Fig. 9 Main effect plot and interaction plot for vibrations 
Table 5 Typical frequencies and the number of their appearance

\begin{tabular}{lllllllllllllll}
\hline Freq. (Hz) & IPF & $x$ & $x_{\text {up }}$ & $x_{\text {full }}$ & $x_{\text {down }}$ & $y$ & $y_{\text {up }}$ & $y_{\text {full }}$ & $y_{\text {down }}$ & $z$ & $z_{\text {up }}$ & $z_{\text {full }}$ & $z_{\text {down }}$ & Reason \\
\hline 0 & 0.00 & 59 & 17 & 21 & 21 & 54 & 21 & 21 & 12 & 63 & 21 & 21 & 21 & Nonharmonic component \\
100 & 0.05 & 46 & 15 & 15 & 16 & 22 & 7 & 8 & 7 & - & - & - & - & Electric transformation [54] \\
415 & 0.22 & 47 & 15 & 15 & 17 & 56 & 19 & 18 & 19 & 48 & 17 & 17 & 14 & Machine tool characteristics \\
940 & 0.50 & 54 & 17 & 20 & 17 & 45 & 14 & 18 & 13 & 61 & 20 & 21 & 20 & Frequency of the spindle speed \\
1880 & 1.00 & 57 & 16 & 20 & 21 & 63 & 21 & 21 & 21 & 54 & 21 & 12 & 21 & Frequency of the edge impact \\
2820 & 1.50 & 54 & 21 & 14 & 19 & 47 & 16 & 14 & 17 & 34 & 7 & 16 & 11 & $1.5 \times$ IPF \\
3760 & 2.00 & 62 & 21 & 21 & 20 & 63 & 21 & 21 & 21 & 59 & 21 & 17 & 21 & $2 \times$ IPF \\
4590 & 2.44 & 31 & 6 & 18 & 7 & - & - & - & - & 42 & 16 & 19 & 7 & n/d \\
4700 & 2.50 & 60 & 21 & 20 & 19 & - & - & - & - & 63 & 21 & 21 & 21 & $2.5 \times$ IPF \\
5640 & 3.00 & - & - & - & - & 53 & 21 & 15 & 17 & 63 & 21 & 21 & 21 & $3 \times$ IPF \\
6580 & 3.50 & 42 & 20 & 9 & 13 & - & - & - & - & 6 & 2 & 0 & 4 & $3.5 \times$ IPF \\
7520 & 4.00 & 59 & 21 & 20 & 18 & - & - & - & - & 45 & 10 & 17 & 18 & $4 \times$ IPF \\
\hline
\end{tabular}

Ten frequencies of the highest amplitude were collected by means of a LabVIEW software application developed by the authors. FFT is performed on a steady-state section of the milling process, and the 10 largest amplitudes are automatically determined and recorded together with associated frequency values. The program performs a total of 10 maximum searches, whereby the previously collected components and their closest environment $( \pm 5 \mathrm{~Hz})$ are always removed. Thus - from a technological point of view - different frequencies are collected.

Table 5 shows frequency values typical of the process and summarises the number of their appearance in the investigated force component signals of 63 different parameter combinations. In Table 5, $x, y$, and $z$ mean different force directions (as can be seen in Fig. 1, where the direction of the feed force is designated by $y$ ), and the number of their appearance at each milling strategy is also shown in cells with a grey background.

The frequencies were analysed, and their relation to the impact frequency of the cutting edges (IPF) was examined. In our previous study [37], it was found that, in the case of a tool of good condition, the exact multiple frequencies of IPF appear.

$\mathrm{IPF}=\frac{n z}{60}(\mathrm{~Hz})$

where $n$ is the rotation speed $(1 / \mathrm{min})$, and $z$ is the number of edges.

Based on the Eq. (6), IPF should be as high as $1910 \mathrm{~Hz}$, which would mean a spindle speed frequency of $955 \mathrm{~Hz}$. According to the measured signal, the frequency of spindle speed is uniformly $940 \mathrm{~Hz}$, which means a difference of $1.6 \%$ from the set speed. This error can originate from the imperfection of the control system of the machine tool. Given this, the standard IPF value was $1880 \mathrm{~Hz}$.

The frequencies listed here are the most dominant ones characterising the micro milling process. They are mostly present among the frequencies of the 10 highest amplitudes concerning the investigated parameter combinations (at a constant cutting speed of $v_{c}=90 \mathrm{~m} / \mathrm{min}$ ). All of the recorded signals contain disturbing frequencies originating from the environment and from the electrical network. The main frequencies characterising the micro milling process arise from

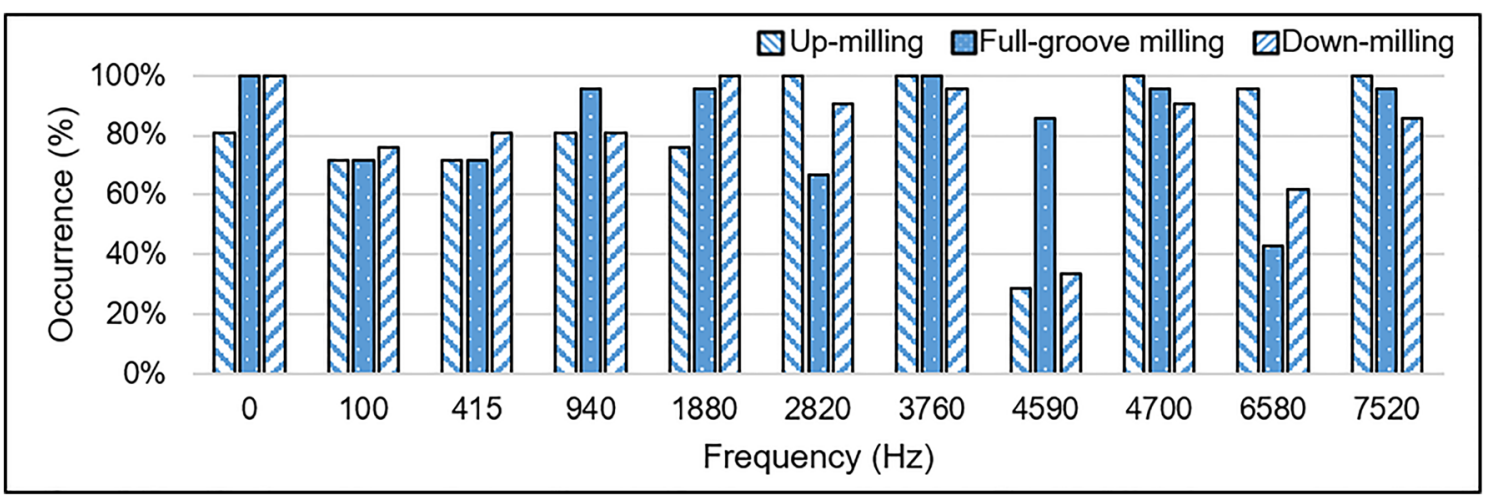

Fig. 10 Percentage rate of the appearance of 10 dominant frequencies of highest amplitude in the $F_{x}$ force signal 


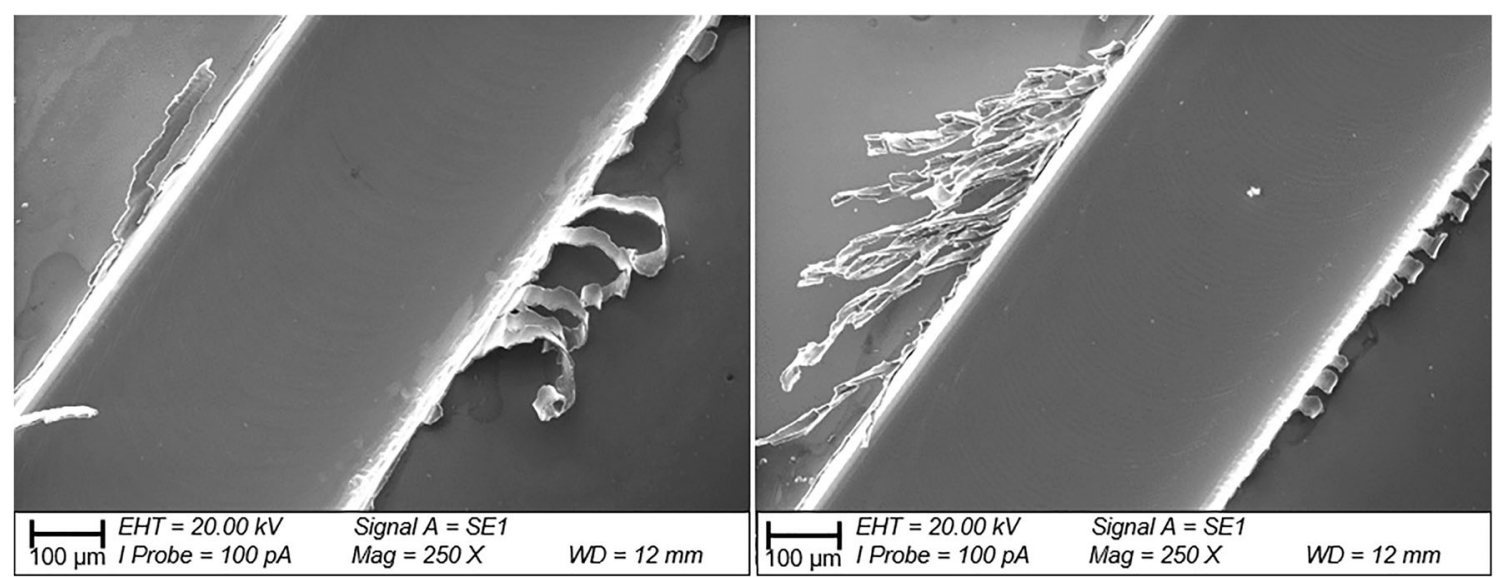

Fig. 11 Scanning electron microscope images of the groove prepared when $a_{p}=0.1 \mathrm{~mm}$ at $f_{z}=2 \mu \mathrm{m}$ and at $f_{z}=6 \mu \mathrm{m}$

the rotation of the main spindle, and from the impact of the cutting edges of the micro milling tool. Due to strong vibrations and the periodic excitation of the micro milling process, the dominant frequency characterising the process differs from IPF: namely, it is two times larger $(3760 \mathrm{~Hz})$. The description of similar circumstances can be found in the study prepared by Singh and Singh [39] and by Jáuregui et al. [37].

In percentages, Fig. 10 shows the appearance of dominant frequencies of the $F_{x}$ force component signal in the case of different milling strategies (see Fig. 10 based on the data shown in Table 5). Based on the diagram shown in Fig. 10, it can be concluded that only the frequencies of 2820, 4590, and $6580 \mathrm{~Hz}$ show larger differences in the case of different milling strategies. These differences do not play a significant role: in the case of component " $z$ ", the $2820 \mathrm{~Hz}$ frequency is less significant, and the other two frequencies (4590 and $6580 \mathrm{~Hz}$ ) do not appear in the other two force components (as shown in Table 5). Thus, it can be stated that there is no significant difference between the diverse milling strategies considering dominant frequencies.

\subsection{Analysis of burr formation}

Relatively, strong burr formation characterising the micro milling process is also the result of the size effect, which is a significant limitation of the process. Due to small dimensions, burr removal is quite difficult. In the scope of this study, top burr width was measured using a digital microscope of $\times 500$ nominal magnification. An average of three measurements at different places was used for the analysis in the scope of the present experiments. Within the investigated range of parameters, changes in the size of the burr on one side of the grooves were relative high (between $\sim 0$ and $300 \mu \mathrm{m}$ ).

Strong burr formation during the process is well illustrated by the images produced using a scanning electron microscope (Fig. 11). Based on the images, it can be stated that the size of the burr falls in the range of the diameter of the tool.

Burr on the up-milling side decreases with the increase of feed per tooth, and it increases at $a_{p}=50$ and $a_{p}=100 \mu \mathrm{m}$ depth of cut on the down-milling side (Fig. 12). As shown on the diagrams, the depth of cut is exactly the same as the corner radius, which causes the most significant burr. Top burr size was smaller in the case of the down-milling process: when the depth of cut was smaller than the corner radius. Saptaji and Subbiah $[44,55]$ established that burr can be reduced by using a tapered tool. In this case, a similar effect can be achieved using $a_{p}=25 \mu \mathrm{m}$ commercially available micro tools with a corner radius.

Burr formation on the up-milling side showed the same tendencies and almost the same size both in the case of edge
Fig. 12 Variation of top burr sizes when using different cutting parameters: milling using half diameter of the tool in the case of a up-milling and $\mathbf{b}$ down-milling
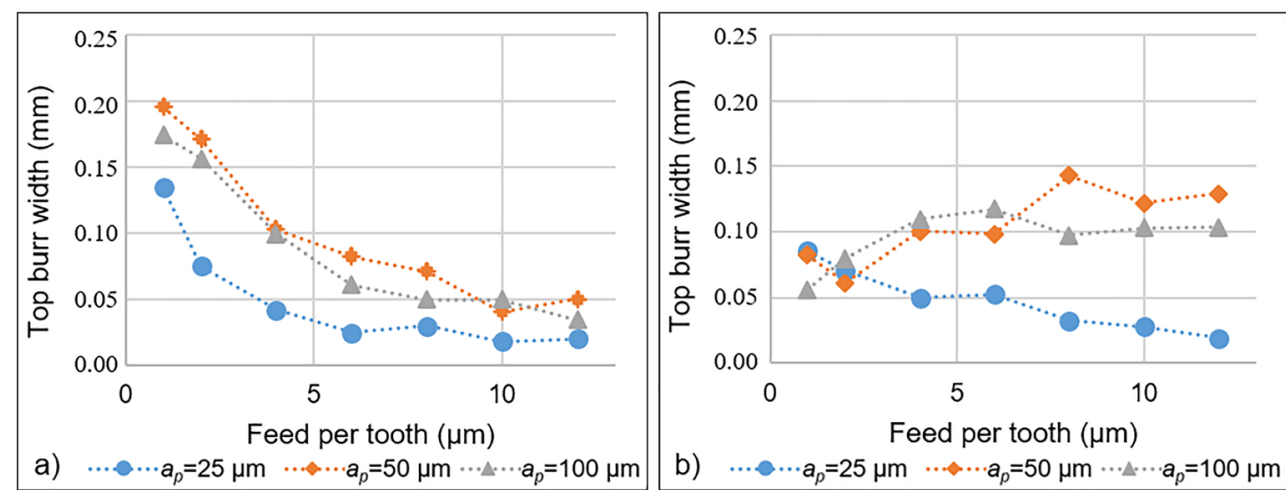
Fig. 13 Top burr width when using different milling strategies: in the case of a milling using half diameter of the tool, and in the case of $\mathbf{b}$ full-groove milling
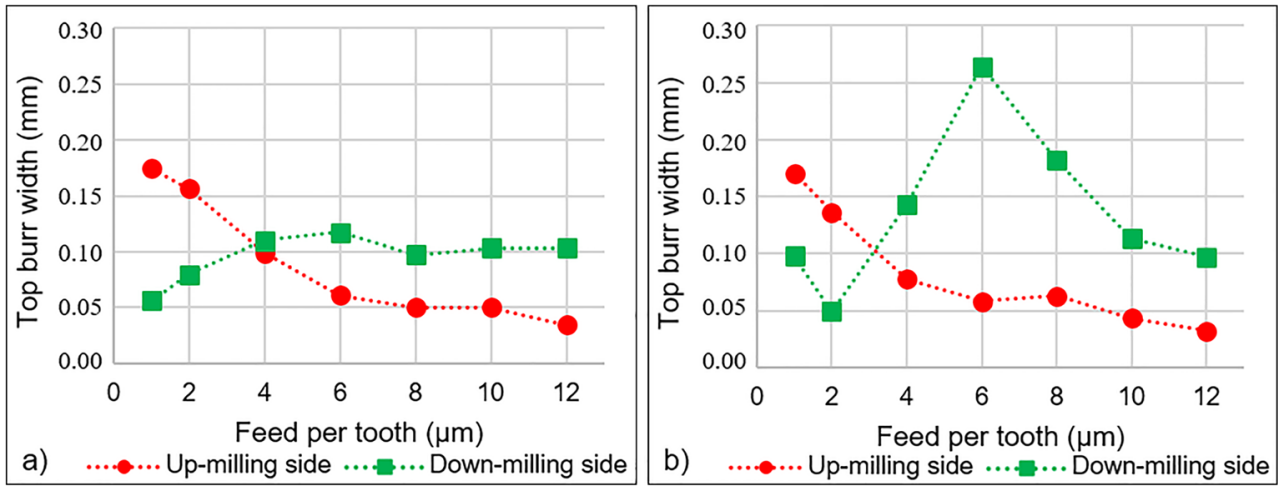

milling with half diameter and in the case of groove milling with full diameter of the tool. On the contrary, larger burr size was found in the case of groove milling using a full diameter of the tool in a number of cases at the down-milling side. An example of this phenomenon is shown in Fig. 13b in the case of $f_{z}=6 \mu \mathrm{m}$. At this feed per tooth value, similar anomalies were found as in the case of force and vibration measurements. It follows from this that this combination of cutting parameters should be avoided, particularly because an increase of feed rate has a beneficial effect on productivity.

When $a_{p}=25 \mu \mathrm{m}$, top burr of roughly the same size is formed in the case of both milling strategies. In other cases, however, it was found that lower feed per tooth values cause larger burr on the up-milling side, similarly to the conventional milling process. Nevertheless, in the case of $f_{z}=4 \mu \mathrm{m}$ feed per tooth, there will be a change, and burr on the down-milling side will be larger (Fig. 13). This change occurs when feed per tooth and the cutting edge radius of the tool are approximately the same. In fact, the said change can offer a possible explanation of different opinions in the literature regarding the dominant burr side in the case of micro milling.

In the case of full-groove milling using $a_{p}=50$ and $a_{p}=$ $100 \mu \mathrm{m}$, the decreasing curve of up-milling burr and the increasing curve of down-milling burr cross each other at around $f_{z}=4 \mu \mathrm{m}$. It can be seen in Fig. 13 that the dominant burr side relocates from the up-milling side to the down-

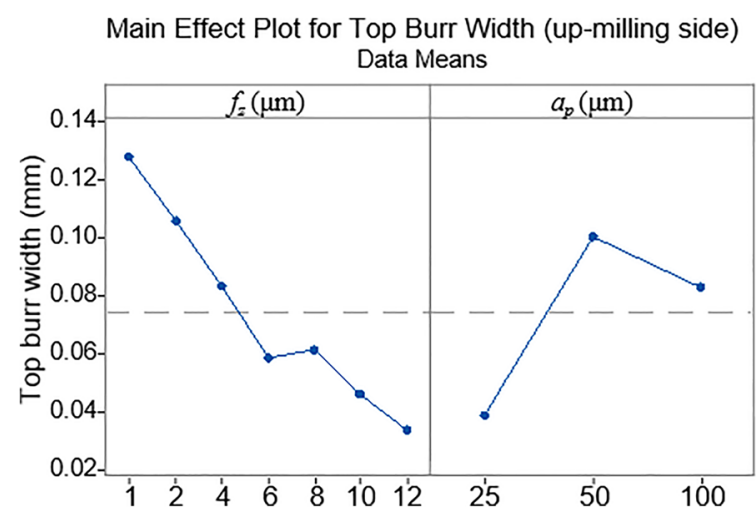

milling side when feed rate is increased in the case of fullgroove milling.

Measured data related to burr formation were also analysed using ANOVA (Fig. 14). Based on the main effect plots (Fig. 14), it can be stated that an increase in feed per tooth results in decreased burr on the up-milling side. The main effect of $f_{z}$ is $0.094 \mathrm{~mm}$ ( $F$ value: $24.12, P$ value: 0.000$)$, while the main effect of $a_{p}$ is $0.061 \mathrm{~mm}$ ( $F$ value: $4.38, P$ value: 0.052$)$, but the latter is not statistically significant. Concerning both milling strategies, it was found that the larger the depth of cut, the larger the burr size. The most unfavourable burr was formed in the case of a depth of cut equal to the corner radius. In the case of burr on the downmilling side, the main effect of the feed per tooth is $0.098 \mathrm{~mm}(F$ value: $1.20, P$ value: 0.289$)$. An increase in the parameters results in increased burr, but the trend is not monotonous. The main effect of $a_{p}$ is $0.127 \mathrm{~mm}$ ( $F$ value: $2.21, P$ value: 0.156 ). Based on the investigations in the scope of this study, it can be concluded that the parameters have no statistically significant effects on burr formation on the down-milling side.

As a summary, it is concluded that up-milling side burr depends primarily on the value of feed per tooth, and secondarily on the depth of cut, while in the case of down-milling side burr the effects of these parameters are reversed.

Moreover, the results of ANOVA show that the interaction of different cutting parameters does not exert statistically significant effects (Fig. 15): at the down-milling side burr, $F$ value and $P$ value are 0.27 and 0.611 ,
Main Effect Plot for Top Burr Width (down-milling side)

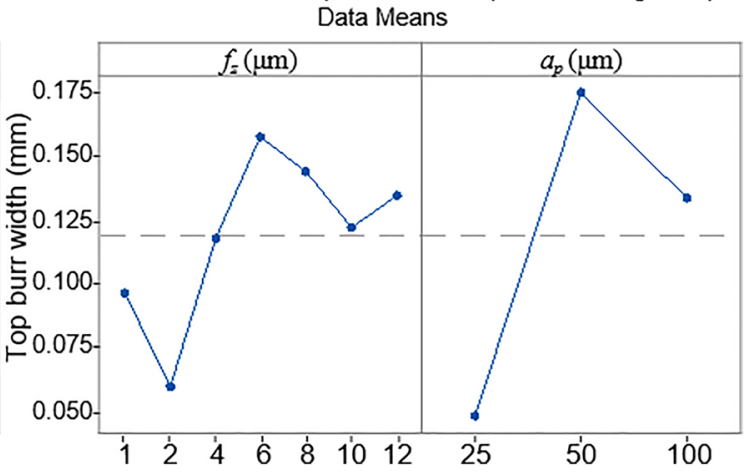

Fig. 14 Main effect plots for top burr width 

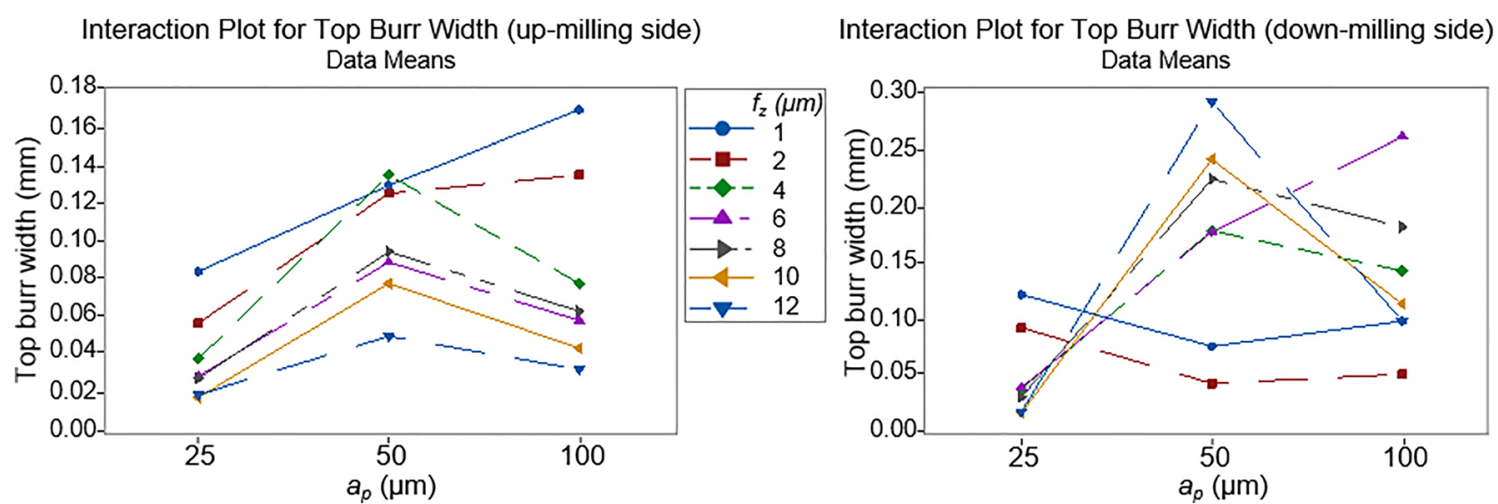

Fig. 15 Interaction plots for burr formation

respectively, while at the up-milling side burr, they are 2.34 and 0.14 , respectively.

\subsection{Surface quality}

In order to characterise the surface quality of machined parts, average surface roughness $\left(R_{a}\right)$ and roughness depth $\left(R_{z}\right)$ are typically applied in the industry $[56,57]$. The surface quality of micro milled structures depends primarily on the cutting parameters applied. However, in the case of micro milling, an excessive reduction in the feed per tooth value is not a solution, as minimal chip thickness and the ploughing effect exert limitations on the process. In the scope of the present study, surface roughness was measured using Mitutoyo SJ 400 . With respect to the surface texture caused by milling kinematics, roughness was measured in the central line of full-grooves. On the other hand, shoulder milling strategies using half diameter of the tool are not suitable for accurate comparison because of the resulting geometry. All data displayed below are based on the average of three measurements. The results of roughness measurement are shown in Fig. 16.

A regular increase in the values can be observed only in the case of $a_{p}=25 \mu \mathrm{m}$. As opposed to burr formation, referent values are favourable at $a_{p}=50 \mu \mathrm{m}$. Both roughness parameters reach a minimum at $f_{z}=4 \mu \mathrm{m}$. In this case, the set feed

Fig. 16 Surface roughness of the bottom of the machined structure in the case of full-groove milling when using different cutting parameter combinations
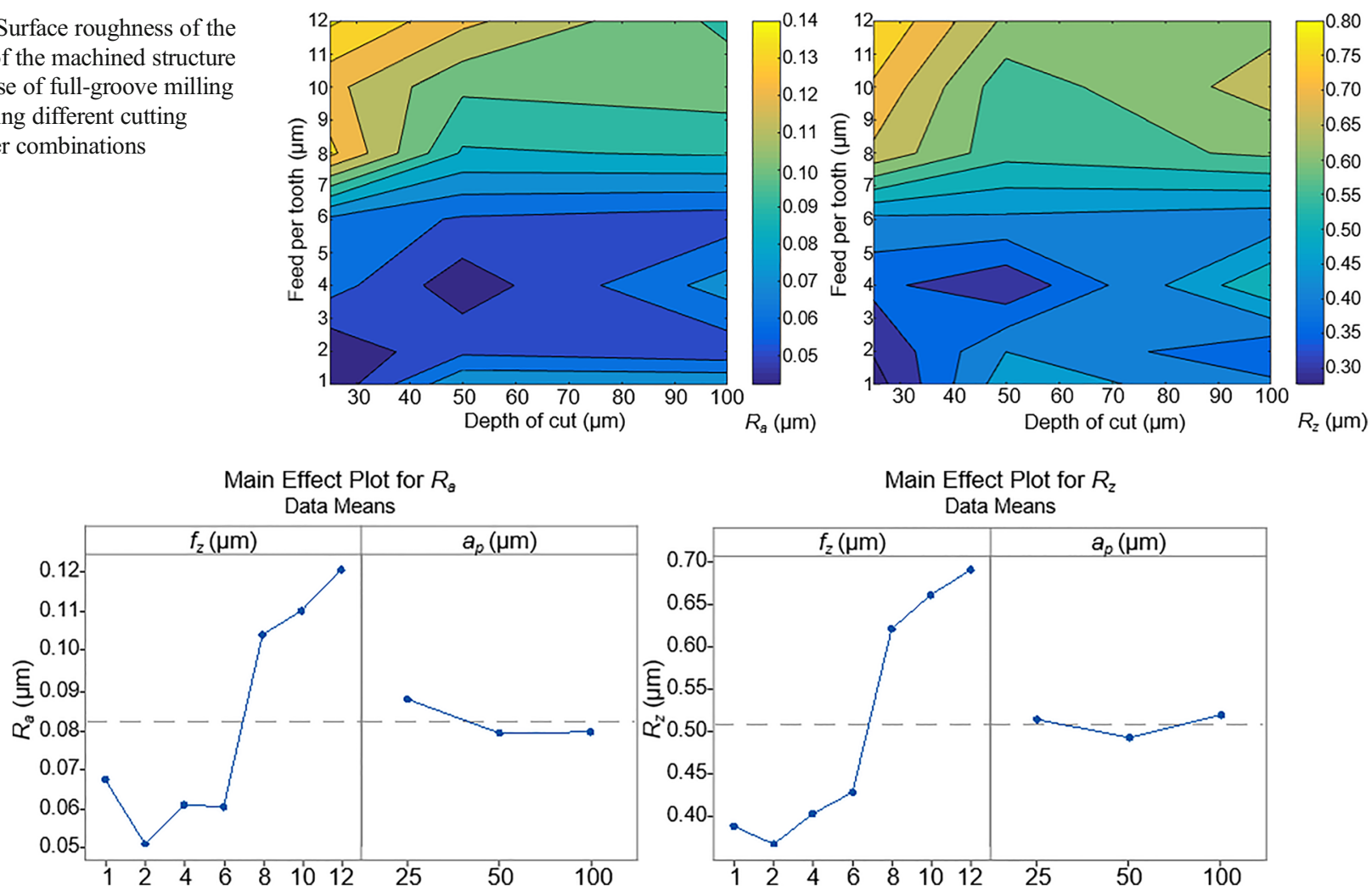

Fig. 17 Main effect plots for surface roughness parameters 


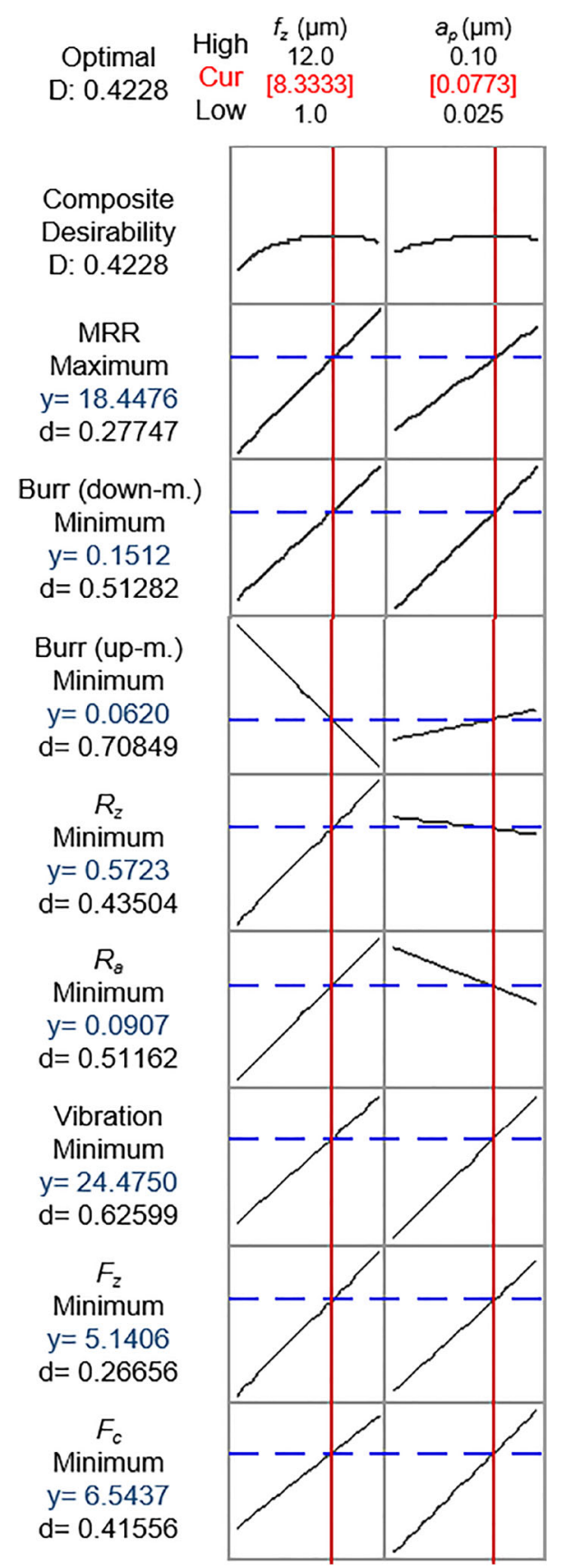

Fig. 18 Result of optimisation

per tooth value is the same as the cutting edge radius. Using the same material, similar results were obtained in Aramcharoen and Mativenga's study [20].

According to the ANOVA analysis performed in the scope of the study, feed per tooth has a significant effect on results in the examined range of cutting parameters. The depth of cut has no significant effect on surface roughness parameters (Fig. 17). Based on the graphs, it can be observed that there is a local minimum of $R_{a}$ and $R_{z}$ at $f_{z}=2 \mu \mathrm{m}$. A potential reason for this can be the fact that, considering cutting edge radius, the set value of feed per tooth is larger than minimal
Table 6 Response optimisation by Minitab software

\begin{tabular}{llllll}
\hline Response & Goal & $\begin{array}{l}\text { Lower } \\
\text { value }\end{array}$ & $\begin{array}{l}\text { Target } \\
\text { value }\end{array}$ & $\begin{array}{l}\text { Upper } \\
\text { value }\end{array}$ & Weight \\
\hline MRR $\left(\mathrm{mm}^{3} / \mathrm{min}\right)$ & Maximum & 0.7162 & 34.3776 & 2 \\
Burr down-m. $(\mu \mathrm{m})$ & Minimum & 0.0147 & 0.29500 & 1 \\
Burr up-m. $(\mu \mathrm{m})$ & Minimum & 0.0173 & 0.17067 & 1 \\
$R_{z}(\mu \mathrm{m})$ & Minimum & 0.2767 & 0.80000 & 1 \\
$R_{a}(\mu \mathrm{m})$ & Minimum & 0.0420 & 0.14167 & 1 \\
Vibration $\left(\mathrm{m} / \mathrm{s}^{2}\right)$ & Minimum & 0.8530 & 4.98800 & 1 \\
$F_{z}(\mathrm{~N})$ & Minimum & 2.8890 & 5.95900 & 1 \\
$F_{c}(\mathrm{~N})$ & Minimum & 1.7290 & 9.96700 & 1 \\
\hline
\end{tabular}

chip thickness. Below this value, deterioration of surface quality is observed. The main effects of $f_{z}$ on parameters $R_{a}$ and $R_{z}$ were $0.069 \mu \mathrm{m}$ ( $F$ value: $35.9, P$ value: 0.000$)$ and $0.32 \mu \mathrm{m}(F$ value: $42.84, P$ value: 0.000$)$, respectively. In addition, the combined effect of $f_{z}$ and $a_{p}$ on $R_{a}$ is significant ( $F$ value: 6.55, $P$ value: 0.020 ), although the same null hypothesis at $R_{z}$ cannot be rejected ( $F$ value: $3.54, P$ value: 0.077 ).

\subsection{Optimisation}

Based on the results of the cutting experiments, optimal machining parameters were determined in order to offer a costeconomic production solution to the industry. The outcome of the optimisation is shown in Fig. 18. The results presented on the figures were calculated using Minitab software for fullgroove milling. Table 6 shows the criteria applied for optimisation. The given values was calculated by the software. The forces, vibrations, the surface quality $\left(R_{a}, R_{z}\right)$, and burr formation (on both the down- and up-milling sides) were minimised while productivity (MRR) was maximised. Considering the importance of cost-economic operation and efficiency, productivity was taken into account with double weight. Based on the above-mentioned aspects, the optimal parameter combination in the examined parameter range is $v_{c}=90 \mathrm{~m} / \mathrm{min}$, $f_{z}=8.33 \mu \mathrm{m}$, and $a_{p}=77 \mu \mathrm{m}$.

A sample run was carried out with the determined optimal parameter combination. The results of this setting are in good agreement with the trends reported in this article. The average values of the examined characteristics are as follows: $F_{c}=$ $6.364 \mathrm{~N}, F_{z}=3.995 \mathrm{~N}$, Acceleration $=9.815 \mathrm{~m} / \mathrm{s}^{2}, R_{a}=$ $0.078 \mu \mathrm{m}, R_{z}=0.51 \mu \mathrm{m}$, and the top burr widths on the down-milling and up-milling sides are $0.049 \mu \mathrm{m} 0.067 \mu \mathrm{m}$, respectively.

\section{Summary}

The main aims of this research included the following: to provide a deeper understanding of the micro milling process, 
and to offer a method for achieving better quality in the framework of reproducible machining processes. Systematic series of experiments were designed and carried out in order to investigate the effects of the most relevant cutting parameters and milling strategies on the special characteristics of the micro milling process, on cutting forces, on vibration, on burr formation, and on surface quality. A 5-axis micromachining centre with a maximum spindle speed of $60,000 \mathrm{rpm}$ and a coated carbide micro milling tool with a diameter of $500 \mu \mathrm{m}$ were applied. In the scope of the experiments, hardened AISI H13 hot-work tool steel with 50 HRC hardness was used as testing material.

- Power regression mathematical models were fitted on the values of measured cutting forces in the case of different milling strategies. The models prepared in the scope of this experiment offer good approximation of the measured data, with correlations falling between 97.25 and $99.28 \%$.

- In the case of down-milling at $a_{p}=25 \mu \mathrm{m}, F_{c}$ shows an increase of only $29.74 \%$, while productivity increases up to 12 times. In the case of up-milling, forces will double under the same conditions. Therefore, considering the resultant forces and economic aspects, higher feed per tooth values seem expedient.

- The amplitudes of vibration show significant differences in the characteristics of the micro milling process at $a_{p}=$ $100 \mu \mathrm{m}$ compared to the other two depths of cut values $\left(a_{p}=25\right.$ and $\left.a_{p}=50\right)$. However, up to $f_{z}=8 \mu \mathrm{m}$, it is advisable to choose $a_{p}=100 \mu \mathrm{m}$ rather than $a_{p}=50 \mu \mathrm{m}$, because the vibration characteristics of the former settings are more favourable, let alone the accompanying double productivity associated with it.

- Based on ANOVA, the examined micro milling parameters (feed per tooth, depth of cut) - and likewise the interaction between them - have a statistically significant effect on forces and vibrations.

- An FFT analysis was applied in order to identify and analyse the frequencies characterising the process in detail.

- Strong correlation between corner radius and burr formation was identified. If the selected depth of cut is smaller than the corner radius of the tool, burr will be smaller. In case the value of the depth of cut is at least as high as the corner radius of the tool, the dominant burr side will depend on the value of $f_{z}$. If the value of the feed per tooth is smaller than the cutting edge radius, then burr on the upmilling side will be larger; and conversely, if this value is larger, then burr formation will be concentrated on the down-milling side.

- As shown by ANOVA, the roughness of the surfaces produced using full-groove milling is almost exclusively dependent on feed per tooth.

- In the range of the investigated cutting parameters, an optimal parameter combination was established by way of taking economic aspects into account. Given this, the optimal parameters are as follows: $v_{c}=90 \mathrm{~m} / \mathrm{min}, f_{z}=$ $8.33 \mu \mathrm{m}$, and $a_{p}=77 \mu \mathrm{m}$.

Acknowledgements Open access funding provided by Budapest University of Technology and Economics (BME). The research reported in this paper has been supported by the National Research, Development and Innovation Fund (TUDFO/51757/2019-ITM, Thematic Excellence Program). The results introduced in this paper are applied in the project no. ED_18-22018-0006 that has been implemented with the support provided from the National Research, Development and Innovation Fund of Hungary, financed under the (publicly funded) funding scheme according to Section 13. § (2) of the Scientific Research, Development and Innovation Act. The authors wish to gratefully acknowledge support by Fraisa and Böhler. We extend our especial thanks to our colleague, Mr. Ádám Jacsó for his support in carrying out experiments and performing measurements.

Open Access This article is licensed under a Creative Commons Attribution 4.0 International License, which permits use, sharing, adaptation, distribution and reproduction in any medium or format, as long as you give appropriate credit to the original author(s) and the source, provide a link to the Creative Commons licence, and indicate if changes were made. The images or other third party material in this article are included in the article's Creative Commons licence, unless indicated otherwise in a credit line to the material. If material is not included in the article's Creative Commons licence and your intended use is not permitted by statutory regulation or exceeds the permitted use, you will need to obtain permission directly from the copyright holder. To view a copy of this licence, visit http://creativecommons.org/licenses/by/4.0/.

\section{References}

1. Balázs BZ, Szalay T, Takács M (2017) Investigation of micro milled surface characteristics. Proceedings of International Conference on Innovative Technologies 161-164

2. Geier N, Davim JP, Szalay T (2019) Advanced cutting tools and technologies for drilling carbon fibre reinforced polymer (CFRP) composites: a review. Compos Part A-Appl S 125:105552. https:// doi.org/10.1016/j.compositesa.2019.105552

3. Jin X, Altintas Y (2012) Prediction of micro-milling forces with finite element method. J Mater Process Technol 212:542-552. https://doi.org/10.1016/j.jmatprotec.2011.05.020

4. Takács M (2006) Sokkristályos ötvözetek mikroforgácsolása keményfém szármaróval. Dissertation, Budapest University of Technology and Economics

5. Kumar P, Bajpai V, Singh R (2017) Burr height prediction of Ti6Al4V in high speed micro-milling by mathematical modeling. Manuf Lett 11:12-16. https://doi.org/10.1016/j.mfglet.2016.10.001

6. Gao S, Pang S, Jiao L, Yan P, Luo Z, Yi J, Wang X (2017) Research on specific cutting energy and parameter optimization in micromilling of heat-resistant stainless steel. Int J Adv Manuf Technol 89:191-205. https://doi.org/10.1007/s00170-016-9062-x

7. Aramcharoen A, Mativenga PT, Yang S, Cooke KE, Teer DG (2008) Evaluation and selection of hard coatings for micro milling of hardened tool steel. Int J Mach Tool Manu 48:1578-1584. https://doi.org/10.1016/j.ijmachtools.2008.05.011

8. Bissacco G, Hansen HN, De Chiffre L (2005) Micromilling of hardened tool steel for mould making applications. J Mater Process Technol 167:201-207. https://doi.org/10.1016/j. jmatprotec.2005.05.029 
9. de Oliveira FB, Rodrigues AR, Coelho RT, de Souza AF (2015) Size effect and minimum chip thickness in micromilling. Int J Mach Tool Manu 89:39-54. https://doi.org/10.1016/j.ijmachtools.2014. 11.001

10. Sun Q, Cheng X, Liu Y, Yang X, Li Y (2017) Modeling and simulation for micromilling mechanisms. Procedia Engineer 174:760 766. https://doi.org/10.1016/j.proeng.2017.01.219

11. Dib MHM, Duduch JG, Jasinevicius RG (2018) Minimum chip thickness determination by means of cutting force signal in micro endmilling. Precis Eng 51:244-262. https://doi.org/10.1016/j. precisioneng.2017.08.016

12. Biró I, Szalay T (2017) Extension of empirical specific cutting force model for the process of fine chip-removing milling. Int J Adv Manuf Technol 88:2735-2743. https://doi.org/10.1007/s00170016-8957-x

13. Ramos AC, Autenrieth H, Strauß T, Deuchert M, Hoffmeister J, Schulze V (2012) Characterization of the transition from ploughing to cutting in micro machining and evaluation of the minimum thickness of cut. J Mater Process Technol 212:594-600. https://doi.org/ 10.1016/j.jmatprotec.2011.07.007

14. Kang IS, Kim JS, Seo YW (2010) Investigation of cutting force behaviour considering the effect of cutting edge radius in the microscale milling of AISI 1045 steel. P I Mech Eng B-J Eng. https://doi. org/10.1243/09544054JEM1762

15. Vogler MP, DeVor RE, Kapoor SG (2005) On the modeling and analysis of machining performance in micro-Endmilling, part I: surface generation. J Manuf Sci Eng 126:685-694. https://doi.org/ $10.1115 / 1.1813470$

16. Malekian M, Mostofa MG, Park SS, Jun MBG (2012) Modeling of minimum uncut chip thickness in micro machining of aluminum. J Mater Process Technol 212:553-559. https://doi.org/10.1016/j. jmatprotec.2011.05.022

17. Woon KS, Rahman M, Fang FZ, Neo KS, Liu K (2008) Investigations of tool edge radius effect in micromachining: a FEM simulation approach. J Mater Process Technol 195:204 211. https://doi.org/10.1016/j.jmatprotec.2007.04.137

18. Liu X, DeVor RE, Kapoor SG (2005) An analytical model for the prediction of minimum chip thickness in micromachining. J Manuf Sci Eng 128:474-481. https://doi.org/10.1115/1.2162905

19. Jacso A, Matyasi G, Szalay T (2019) The fast constant engagement offsetting method for generating milling tool paths. Int J Adv Manuf Technol 103:4293-4305. https://doi.org/10.1007/s00170019-03834-8

20. Aramcharoen A, Mativenga PT (2009) Size effect and tool geometry in micromilling of tool steel. Precis Eng 33:402-407. https:// doi.org/10.1016/j.precisioneng.2008.11.002

21. Li KM, Chou SY (2010) Experimental evaluation of minimum quantity lubrication in near micro-milling. J Mater Process Technol 210:2163-2170. https://doi.org/10.1016/j.jmatprotec. 2010.07.031

22. Mian AJ, Driver N, Mativenga PT (2011) Identification of factors that dominate size effect in micro-machining. Int J Mach Tool Manu 51:383-394. https://doi.org/10.1016/j.ijmachtools.2011. 01.004

23. Wang Y, Zou B, Wang J, Wu Y, Huang C (2020) Effect of the progressive tool wear on surface topography and chip formation in micro-milling of Ti-6Al-4V using Ti(C7N3)-based cermet micro-mill. Tribol Int 141:105900. https://doi.org/10.1016/j.triboint. 2019.105900

24. Vipindas K, Mathew J (2019) Wear behavior of TiAlN coated WC tool during micro end milling of Ti-6Al-4V and analysis of surface roughness. Wear 424-425:165-182. https://doi.org/10.1016/j.wear. 2019.02 .018

25. Lu X, Wang F, Jia Z, Si L, Zhang C, Liang SY (2017) A modified analytical cutting force prediction model under the tool flank wear effect in micro-milling nickel-based superalloy. Int J Adv Manuf Technol 1-8. https://doi.org/10.1007/s00170-017-0001-2

26. Aslantas K, Hopa HE, Percin M, Ucun İ, Çicek A (2016) Cutting performance of nano-crystalline diamond (NCD) coating in micromilling of Ti6Al4V alloy. Precis Eng 45:55-66. https://doi.org/10. 1016/j.precisioneng.2016.01.009

27. Zhu K, Yu X (2017) The monitoring of micro milling tool wear conditions by wear area estimation. Mech Syst Signal Pr 93:80-91. https://doi.org/10.1016/j.ymssp.2017.02.004

28. Uhlmann E, Oberschmidt D, Löwenstein A, Kuche Y (2016) Influence of cutting edge preparation on the performance of micro milling tools. Proc CIRP 46:214-217. https://doi.org/10.1016/j. procir.2016.03.204

29. Afazov SM, Zdebski D, Ratchev SM, Segal J, Liu S (2013) Effects of micro-milling conditions on the cutting forces and process stability. J Mater Process Technol 213:671-684. https://doi.org/10. 1016/j.jmatprotec.2012.12.001

30. Wu X, Li L, He N, Yao C, Zhao M (2016) Influence of the cutting edge radius and the material grain size on the cutting force in micro cutting. Precis Eng 45:359-364. https://doi.org/10.1016/j. precisioneng.2016.03.012

31. Zhou L, Peng F, Yan R, Dong Q, Yang C (2015) Prediction and experimental validation of micro end-milling forces with finite element method. Lect Notes Artif Int 9245:664-675. https://doi.org/ 10.1007/978-3-319-22876-1_58

32. Takács M, Balázs BZ, Jáuregui JC (2017) Dynamical aspects of micro milling process. Proceedings of International Conference on Innovative Technologies 181-184

33. Jun MB, Liu X, DeVor RE, Kapoor SG (2006) Investigation of the dynamics of microend milling - part I: model development. J Manuf Sci Eng 128:893-900. https://doi.org/10.1115/1.2193546

34. Zhang X, Yu T, Wang W (2018) Prediction of cutting forces and instantaneous tool deflection in micro end milling by considering tool run-out. Int J Mech Sci 136:124-133. https://doi.org/10.1016/j. ijmecsci.2017.12.019

35. Wang F, Cheng X, Liu Y, Yang X, Meng F (2017) Micromilling simulation for the hard-to-cut material. Procedia engineer, 13th global congress on manufacturing and management Zhengzhou, China 28-30 November, 2016 174:693-699. https://doi.org/10. 1016/j.proeng.2017.01.209

36. Mamedov A, Layegh KSE, Lazoglu I (2013) Machining forces and tool deflections in micro milling. Proc CIRP 8:147-151. https://doi. org/10.1016/j.procir.2013.06.080

37. Jáuregui JC, Reséndiz JR, Thenozhi S, Szalay T, Jacsó Á, Takács M (2018) Frequency and time-frequency analysis of cutting force and vibration signals for tool condition monitoring. IEEE Access 6: 6400-6410. https://doi.org/10.1109/ACCESS.2018.2797003

38. Yilmaz EE, Budak E, Özgüven HN (2016) Modeling and measurement of micro end mill dynamics using inverse stability approach. Proc CIRP 46:242-245. https://doi.org/10.1016/j.procir. 2016.04.114

39. Singh KK, Singh R (2018) Chatter stability prediction in highspeed micromilling of Ti6A14V via finite element based microend mill dynamics. Adv Manuf 6:95-106. https://doi.org/10.1007/ s40436-018-0210-4

40. Kiswanto G, Zariatin DL, Ko TJ (2014) The effect of spindle speed, feed-rate and machining time to the surface roughness and burr formation of aluminum alloy 1100 in micro-milling operation. J Manuf Process 16:435-450. https://doi.org/10.1016/j.jmapro. 2014.05.003

41. Kumar P, Kumar M, Bajpai V, Singh NK (2017) Recent advances in characterization, modeling and control of burr formation in micromilling. Manuf Lett 13:1-5. https://doi.org/10.1016/j.mfglet.2017. 04.002 
42. Zhang T, Liu Z, Xu C (2013) Influence of size effect on burr formation in micro cutting. Int J Adv Manuf Technol 68:1911-1917. https://doi.org/10.1007/s00170-013-4801-8

43. Wu X, Li L, He N (2017) Investigation on the burr formation mechanism in micro cutting. Precis Eng 4:191-196. https://doi.org/10. 1016/j.precisioneng.2016.08.004

44. Saptaji K, Subbiah S (2017) Burr reduction of micro-milled microfluidic channels mould using a tapered tool. Procedia Engineer 184:137-144. https://doi.org/10.1016/j.proeng.2017. 04.078

45. Biermann D, Steiner M (2012) Analysis of micro Burr formation in austenitic stainless steel X5CrNi18-10. Proc CIRP 3:97-102. https://doi.org/10.1016/j.procir.2012.07.018

46. Piquard R, D'Acunto A, Laheurte P, Dudzinski D (2014) Micro-end milling of NiTi biomedical alloys, burr formation and phase transformation. Precis Eng 38:356-364. https://doi.org/10.1016/j. precisioneng.2013.11.006

47. Komatsu T, Yoshino T, Matsumura T, Torizuka S (2012) Effect of crystal grain size in stainless steel on cutting process in micromilling. Proc CIRP 1:150-155. https://doi.org/10.1016/j. procir.2012.04.026

48. Bai Y, Chaudhari A, Wang H (2020) Investigation on the microstructure and machinability of ASTM A131 steel manufactured by directed energy deposition. J Mater Process Technol 276:116410. https://doi.org/10.1016/j.jmatprotec.2019.116410

49. Swain N, Venkatesh V, Kumar P, Srinivas G, Ravishankar S, Barshilia HC (2017) An experimental investigation on the machining characteristics of Nimonic 75 using uncoated and TiAlN coated tungsten carbide micro-end mills. CIRP J Manuf Sci Tec 16:34-42. https://doi.org/10.1016/j.cirpj.2016.07.005

50. Cheng K, Huo D (eds) (2013) Micro cutting: fundamentals and applications. John Wiley \& Sons, Chichester
51. Câmara MA, Rubio JCC, Abrão AM, Davim JP (2012) State of the art on micromilling of materials, a review. J Mater Sci Technol 28: 673-685. https://doi.org/10.1016/S1005-0302(12)60115-7

52. Geier N, Szalay T (2017) Optimisation of process parameters for the orbital and conventional drilling of uni-directional carbon fibrereinforced polymers (UD-CFRP). Measurement 110:319-334. https://doi.org/10.1016/j.measurement.2017.07.007

53. Czampa M, Biró I, Szalay T (2016) A novel machinability test for determining the cutting behaviour of iron-based, carbon-containing and copper-containing powder metallurgy steels (PMS). Int J Adv Manuf Technol 89:3495-3507. https://doi.org/10.1007/s00170016-9313-x

54. Qiu X, Li X, Ai Y, Hansen CH (2002) A waveform synthesis algorithm for active control of transformer noise: implementation. Appl Acoust 63:467-479. https://doi.org/10.1016/S0003-682X(01) 00060-3

55. Saptaji K, Subbiah S, Dhupia JS (2012) Effect of side edge angle and effective rake angle on top burrs in micro-milling. Precis Eng 36:444 450. https://doi.org/10.1016/j.precisioneng.2012.01.008

56. Geier N, Szalay T, Biró I (2018) Trochoid milling of carbon fibrereinforced plastics (CFRP). Proc CIRP 77:375-378. https://doi.org/ 10.1016/j.procir.2018.09.039

57. Czampa M, Biro I, Szalay T (2017) Effects of different cutting conditions on the surface roughness parameters of iron-coppercarbon powder metallurgy composites. Int J Mach Mach Mater 19:440-456. https://doi.org/10.1504/IJMMM.2017.087617

Publisher's note Springer Nature remains neutral with regard to jurisdictional claims in published maps and institutional affiliations. 